\title{
Characteristics of immediate hypersensitivity reaction to paclitaxel-based chemotherapy in gynecologic cancer patients
}

Thitinan Thangwonglers, ${ }^{1,2}$ Wichai Santimaleeworagun, ${ }^{3,4}$ Suwanit Therasakvichya, ${ }^{5}$ Nuttapat Saengsukkasemsak, ${ }^{6}$ Piyarat Pimsi ${ }^{3,4}$

\begin{abstract}
Background: Immediate hypersensitivity reactions (IHRs) are commonly found in patients receiving paclitaxel. Effects of paclitaxel vary because of variable co-therapy or re-challenge with paclitaxel.

Objective: Our objective was to investigate the incidence, patterns, and risk factors for paclitaxel-related IHRs and management of IHRs in gynecologic malignancy patients.

Methods: This retrospective study was performed in gynecologic cancer patients receiving paclitaxel-based regimens at Siriraj hospital from January 2012 to December 2017.

Results: 416 subjects were included and received ranitidine $50 \mathrm{mg}$, dexamethasone $20 \mathrm{mg}$, ondansetron $16 \mathrm{mg}$ intravenously and diphenhydramine $50 \mathrm{mg}$ orally 30 minutes before starting chemotherapy. The incidence of IHRs was $17.79 \%$. IHRs occurring on first exposure to paclitaxel was $81.1 \%$ and occurred within 30 minutes after starting paclitaxel. The most commonly found presentation of IHRs were skin reactions $(86.5 \%)$. In multivariate analysis, age $<54.5$ years, stage of cancer $\geq 2$, and leukocyte cell count $<7.735 \times 10^{9} / \mathrm{L}$ were significantly associated with IHRs. Seventy-two out of 74 patients that recovered from IHRs were reintroduced paclitaxel. Forty-seven patients (97.92\%) of 48 patients with mild reactions were successfully reintroduced to paclitaxel after treatment with chlorpheniramine or other interventions.
\end{abstract}

Conclusion: The incidence of paclitaxel-related IHRs was about one in five. Skin reactions were the most commonly occurring reactions. Younger age, stage of cancer $\geq 2$, and leukocytes $<7.735 \times 10^{9} / \mathrm{L}$ were significant risk factors for IHRs. Patients with IHRs recovered without the use of dexamethasone and antihistamines before the reintroduction of paclitaxel.

Key words: adverse drug reactions, malignancy, paclitaxel, risk factors, hypersensitivity

From:

${ }^{1}$ Directorate of Medical Services, Royal Thai Air Force, Bangkok 10220,

Thailand

${ }^{2}$ College of Pharmacotherapy Thailand, Nonthaburi 11000, Thailand

${ }^{3}$ Department of Pharmacy, Faculty of Pharmacy, Silpakorn University,

Nakhorn Pathom 73000, Thailand

${ }^{4}$ Pharmaceutical Initiative for Resistant Bacteria and Infectious Diseases

Working Group (PIRBIG), Nakhorn Pathom 73000, Thailand

5 Gynecologic Oncology Division, Department of Obstetrics and

Gynecology, Faculty of Medicine Siriraj Hospital, Mahidol University,

Bangkok 10700, Thailand

${ }^{6}$ Department of Pharmacy, Faculty of Medicine Siriraj Hospital, Mahidol University, Bangkok 10700, Thailand

\section{Corresponding author:}

Piyarat Pimsi

Faculty of Pharmacy, Silpakorn University

Sanam Chandra Palace Campus. No.6 RajamankhaNai Road,

PhraPathom Chedi, Muang, Nakhorn Pathom, Thailand, 10400

E-mail: pimsi_p@su.ac.th

\section{Introduction}

Paclitaxel is a member of the taxane class of antineoplastic agents, first described in 1971. ${ }^{1}$ Paclitaxel is an integral part of chemotherapeutic regimens that are widely used in various types of cancers, such as gynecologic, breast, and lung cancers. $^{2-4}$ There are many adverse drug reactions to paclitaxel such as neutropenia, peripheral neuropathy, arrhythmias, alopecia, mucositis, nausea, vomiting, diarrhea, arthralgias, myalgias and hypersensitivity reactions (HSRs). ${ }^{1}$ 
HSRs are commonly found in patients receiving paclitaxel. The severity of paclitaxel-related HSRs can be classified as mild, severe, or lethal. ${ }^{5}$ Paclitaxel-related HSRs usually occur within the first few minutes of starting administration, especially on the first or the second exposure. The symptoms of HSRs can vary from flushing to cutaneous reactions to life-threatening reactions. ${ }^{1,2,6}$ Paclitaxel-related HSRs can be enhanced by cremophor EL (polyoxyethylated castor oil) which is a surfactant for increasing solubility. ${ }^{4-7}$ The incidence of HSRs related to paclitaxel varies. In some studies, up to $30 \%$ of patients treated with paclitaxel suffered from HSRs. ${ }^{2}$ Premedications given prior to paclitaxel therapy can reduce the incidence of HSRs by $10 \%{ }^{2,3}$ Sendo et al. ${ }^{8}$ and Aoyama et al. ${ }^{9}$ investigated risk factors associated with HSRs to paclitaxel and reintroduction of paclitaxel. They demonstrated that postmenopausal status at the time of oophorectomy, history of mild hypersensitivity during the first course, respiratory dysfunction, obesity, age, and premedication were HSR-related risk factors.

There have been few studies related to paclitaxel-induced hypersensitivity syndrome. Moreover, the clinical progression of HSRs varies because of co-treatment with others agent, re-challenge with paclitaxel, or desensitization. ${ }^{10} \mathrm{We}$ aimed to investigate the incidence, patterns, and risk factors for immediate hypersensitivity reactions (IHRs) to paclitaxel in patients treated for gynecologic malignancies and to study the safety of reintroducing paclitaxel among such patients. In our study, IHRs refer to HRSs occurring within 1 hour after paclitaxel administration.

\section{Methods \\ Participants}

In this study, we investigated the incidence of paclitaxelrelated IHRs, pattern of IHRs, risk factors, and reintroduction of paclitaxel. The inclusion criteria for study participants were diagnosis with gynecologic malignancy and administration of paclitaxel-based chemotherapy between January 2012 and December 2017. Subjects that developed HSRs more than one hour after starting paclitaxel administration or had incomplete medical records were excluded.

The study was approved by the Siriraj Institutional Review Board of Human Research Protection Unit at Siriraj Hospital (Approval code: Si 001/2019; start date: January 02, 2019; expiry date: January 01,2020$)$. The requirement for informed consent was waived because of the retrospective nature of the analysis. All 416 participants received ranitidine $50 \mathrm{mg}$ intravenous (IV) injection, dexamethasone (DEX) $20 \mathrm{mg}$ IV injection, ondansetron $16 \mathrm{mg}$ IV injection and diphenhydramine $50 \mathrm{mg}$ orally 30 minutes before starting chemotherapy. Paclitaxel was administered intravenously over 3 hours with a stepwise titration schedule.

\section{Definitions}

IHRs specific to paclitaxel are defined as those that occur within one hour after paclitaxel administration. ${ }^{11}$ Re-challenge is the reintroduction of paclitaxel after the first episode of IHRs by decreased $50 \%$ of infusion rate at IHRs. ${ }^{12}$ Desensitization is the induction of a temporary state of clinical tolerance for paclitaxel, causing a decrease in IHRs. Desensitization protocol were based on the progressive dose of paclitaxel starting at concentration $0.1 \%, 1 \%, 10 \%$ and $88.9 \%$, at 1-hour interval. ${ }^{11}$ Anaphylaxis is a serious, life-threatening and might cause death. In this study, the IHRs patients can be defined as anaphylaxis by using world allergy organization guidelines for the assessment and management of anaphylaxis. ${ }^{13}$ The severity of IHRs was graded using the National Comprehensive Cancer Network (NCCN) guidelines Version 2.2018, ${ }^{14}$ the Common Terminology Criteria for Adverse Events (CTCAE) Version 4.03 and CTCAE Version 5.0, which are shown in Table $\mathbf{1 .}$

\section{Data collections}

The number of patients who received paclitaxel and developed IHRs divided by the total number of patients receiving paclitaxel defined the fraction of paclitaxel-induced IHRs. All participants were reviewed for age, body mass

Table 1. The National Comprehensive Cancer Network (NCCN) 2.2018, the Common Terminology Criteria for Adverse Events (CTCAE) 4.03 and CTCAE 5.0

\begin{tabular}{|c|c|c|}
\hline NCCN 2.2018 & CTCAE 4.03 & CTCAE 5.0 \\
\hline $\begin{array}{l}\text { Mild: hot flushing, rash, pruritus, } \\
\text { pain in chest/abdomen/pelvis/back }\end{array}$ & $\begin{array}{l}\text { Grade 1: transient flushing or rash, } \\
\text { drug fever }<38^{\circ} \mathrm{C} \text {; intervention not indicated }\end{array}$ & Grade 1: systemic intervention not indicated \\
\hline $\begin{array}{l}\text { Severe: shortness of breath, changes blood } \\
\text { pressure requiring treatment, dyspnea, nausea, } \\
\text { vomiting pain in chest/abdomen/pelvis/back, } \\
\text { feeling something wrong }\end{array}$ & $\begin{array}{l}\text { Grade } 2 \text { : intervention or infusion interruption } \\
\text { indicated; responds promptly to symptomatic } \\
\text { treatment; prophylactic medications indicated } \\
\text { for } \leq 24 \text { hours }\end{array}$ & Grade 2: oral intervention indicated \\
\hline \multirow[t]{3}{*}{$\begin{array}{l}\text { Life-threatening: anaphylaxis, generalize hives, } \\
\text { respiratory compromise, severe hypotension, } \\
\text { nausea, vomiting pain in chest/abdomen/pelvis/ } \\
\text { back, feeling something wrong }\end{array}$} & $\begin{array}{l}\text { Grade 3: prolonged; recurrence of symptoms } \\
\text { following initial improvement; hospitalization } \\
\text { indicated for clinical sequelae }\end{array}$ & $\begin{array}{l}\text { Grade 3: bronchospasm hospitalization indicated } \\
\text { for clinical sequelae; intravenous intervention } \\
\text { indicated }\end{array}$ \\
\hline & $\begin{array}{l}\text { Grade } 4 \text { : life-threatening consequences; urgent } \\
\text { intervention indicated }\end{array}$ & $\begin{array}{l}\text { Grade } 4 \text { : life-threatening consequences; urgent } \\
\text { intervention indicated }\end{array}$ \\
\hline & Grade 5: death & Grade 5: death \\
\hline
\end{tabular}

NCCN, National Comprehensive Cancer Network; CTCAE, Common Terminology Criteria for Adverse Events. 
index (BMI), cancer type, stage of cancer, history of allergy to medication, history of asthma, menopausal status, ovariectomy, white blood cell count, and absolute eosinophil count for risk factor analysis. Onset of IHRs, clinical presentation and severity data were collected for describing the pattern of IHRs. After the IHRs patients received paclitaxel re-challenge. If the patients had no symptoms after re-challenge, the patient success to re-challenge. To assess the success rate of paclitaxel re-challenge after a first episode of IHRs, we calculated the success rate of re-challenge by dividing the number of patients who succeeded to re-challenge by the number of patients who underwent paclitaxel re-challenge. The success rate of paclitaxel desensitization was not examined because there were a few patients who underwent desensitization. This was the limitation of this study to prove a success of desensitization protocol.

\section{Statistical analysis}

Descriptive statistics were presented for patient characteristics, incidence of IHRs, the pattern of IHRs and the reintroduction of paclitaxel. Receiver-operator characteristics (ROC) were used to identify the cut off values for some variables. The correlation of IHR risk factors were analyzed by Chi-square or Fisher's exact tests. All significant variables in the univariate analysis were further evaluated in multivariate analysis by logistic regression. Statistical analyses were carried out using $\mathrm{R}$ version 3.6.2 at $\alpha=0.05$ for statistical significance.

\section{Results \\ Patient characteristics}

During the six-year study period, there were 416 gynecologic cancer patients who received paclitaxel-based chemotherapy. Their mean age $( \pm S D)$ was $56.37( \pm 10.68)$ years. The median BMI, leukocyte count, and absolute eosinophil count were $23.81 \mathrm{~kg} / \mathrm{m}^{2}, 7.700 \times 10^{9} / \mathrm{L}$ and $0.120 \times 10^{9} / \mathrm{L}$, respectively. Most of the patients $(89.1 \%)$ received paclitaxel plus carboplatin as their first-line chemotherapy regimen because about $80 \%$ of them were diagnosed with ovarian and uterine cancer. Disease status of enrolled participants was stage I in 122 patients (29.8\%) and stage III in 152 patients (37.2\%). Participants with a history of allergy and asthma comprised 87 patients $(20.9 \%)$ and 10 patients $(2.4 \%)$, respectively. Menopausal status was recorded before receiving chemotherapy, and 273 of 416 patients (65.6\%) were menopausal (Table 2).

\section{Incidence and pattern of paclitaxel-related immediate hyper- sensitivity reactions}

Paclitaxel-related IHRs occurred in 74 out of 416 patients (17.79\%). Among these cases, 60 patients (81.1\%) developed IHRs during the first cycle of paclitaxel-based chemotherapy, and the others developed IHRs during the second chemotherapy cycle. Thirty-two of 74 patients (47.8\%) had an onset of IHRs within the first 5 minutes after starting paclitaxel administration, while the remaining patients had IHRs that occurred within the first thirty minutes. The most common severities were grade $2(86.5 \%)$, grade $3(86.5 \%)$ and mild reactions (64.9\%) according to CTCAE Version 4.03,
Table 2. Baseline characteristics

\begin{tabular}{|c|c|c|}
\hline \multirow[b]{2}{*}{ Characteristics } & All patients & IHRs patients \\
\hline & $\begin{array}{c}\mathrm{N}=416 \\
( \pm \mathrm{SD} / \% / \text { range })\end{array}$ & $\begin{array}{c}\mathrm{N}=74 \\
( \pm \mathrm{SD} / \% / \text { range })\end{array}$ \\
\hline Age, mean \{plus minus\} SD & $56.37( \pm 10.68)$ & $53.10( \pm 10.79)$ \\
\hline Body mass index, median (range) & $\begin{array}{c}23.81 \\
(13-48.6)\end{array}$ & $\begin{array}{c}23.18 \\
(13.8-43.4)\end{array}$ \\
\hline \multicolumn{3}{|l|}{ Cancer type, n (\%) } \\
\hline Ovarian cancer & $228(54.8)$ & $39(52.7)$ \\
\hline Uterine cancer & $120(28.8)$ & $24(32.4)$ \\
\hline Cervical cancer & $60(14.4)$ & $10(13.5)$ \\
\hline $\begin{array}{l}\text { Two primary cancer (Ovarian } \\
\text { cancer }+ \text { Endometrium cancer) }\end{array}$ & $7(1.7)$ & $1(1.4)$ \\
\hline Vulvar cancer & $1(0.2)$ & - \\
\hline \multicolumn{3}{|l|}{ Stage of cancer, n (\%) } \\
\hline I & $122(29.8)$ & $15(20.3)$ \\
\hline II & $57(13.9)$ & $18(24.3)$ \\
\hline III & $152(37.2)$ & $27(36.5)$ \\
\hline IV & $78(19.1)$ & $14(18.9)$ \\
\hline
\end{tabular}

History of allergy (medication, environmental factors, foods, contrast media), n (\%)

$\begin{array}{lcc}\text { Yes } & 87(20.9) & 15(20.3) \\ \text { No } & 329(79.1) & 59(79.7) \\ \text { Asthma, n (\%) } & & \\ \text { Yes } & 10(2.4) & 1(1.4) \\ \text { No } & 406(97.6) & 73(98.6) \\ \text { Postmenopausal, n (\%) } & \\ \text { Yes } & 273(65.6) & 41(55.4) \\ \text { No } & 93(22.4) & 25(33.8) \\ \text { Unknown } & 50(12) & 8(10.8)\end{array}$

Regimen, n (\%)

\begin{tabular}{|c|c|c|}
\hline Paclitaxel/carboplatin & $367(89.1)$ & $64(86.5)$ \\
\hline Paclitaxel/cisplatin & $36(8.7)$ & $10(13.5)$ \\
\hline Paclitaxel single agent & $4(1.0)$ & - \\
\hline Paclitaxel/ifosfamide & $3(0.7)$ & - \\
\hline $\begin{array}{l}\text { Paclitaxel/carboplatin/ } \\
\text { Bevacizumab }\end{array}$ & $2(0.5)$ & - \\
\hline White blood cell, median (range) & $\begin{array}{c}7.700 \\
(2.900-30.80)\end{array}$ & $\begin{array}{c}7.180 \\
(3.200-30.80)\end{array}$ \\
\hline $\begin{array}{l}\text { Absolute eosinophils count, median } \\
\text { (range) }\end{array}$ & $0.120(0-3.184)$ & $0.121(0-1.072)$ \\
\hline
\end{tabular}


Table 3. Initial Clinical manifestations of paclitaxel immediate hypersensitivity reactions.

\section{$\mathrm{N}=\mathbf{7 4}(\%)$}

Chemotherapy cycles with first IHRs

$\begin{array}{lr}\text { Cycle } 1 & 60(81.1 \%) \\ \text { Cycle } 2 & 14(18.9 \%)\end{array}$

Onset of IHRs

$\begin{array}{lc}\leq 5 \text { minutes } & 35(47.3) \\ 6-10 \text { minutes } & 24(32.4) \\ 11-15 \text { minutes } & 12(16.2) \\ 16-30 \text { minutes } & 3(4.1)\end{array}$

16-30 minutes

Severity grading by CTCAE version 4.03

$\begin{array}{cc}1 & 1(1.4) \\ 2 & 64(86.5) \\ 3 & 6(8.1) \\ 4 & 3(4.1) \\ 5 & -\end{array}$

Severity grading by CTCAE version 5.0

\begin{tabular}{lc}
1 & $5(6.8)$ \\
2 & $2(2.7)$ \\
4 & $64(86.5)$ \\
5 & $3(4.1)$ \\
Severity grading by NCCN version 2.2018 & - \\
Mild & \\
Severe & $48(64.9)$ \\
Life-threatening & $19(25.7)$ \\
Clinical manifestation & $7(9.5)$ \\
Skin & \\
$\quad$ Flushing & $64(86.5)$ \\
$\quad$ Pruritus & $55(85.9)$ \\
$\quad$ Maculopapular rash & $5(7.8)$ \\
Angioedema & $4(6.3)$ \\
Gastrointestinal tract (nausea, vomiting, discomfort) & $10(13.5)$ \\
Pain (chest, abdominal, back, headache) & $59(79.7)$ \\
Cardiovascular (hypotension, hypertension, \\
tachycardia) \\
Anaphylaxis & $29(39.2)$ \\
\hline
\end{tabular}

IHRs, immediate hypersensitivity reactions; NCCN, National Comprehensive Cancer Network; CTCAE, Common Terminology Criteria for Adverse Events.
CTCAE Version 5.0 and NCCN Version 2.2018 guidelines, respectively. The most common initial clinical presentations of IHRs included skin reactions $(86.5 \%)$, chest pain $(74.3 \%)$, cardiovascular reaction (39.2\%), and abdominal pain (1.4\%). Seven patients $(9.5 \%)$ out of 74 developed anaphylaxis within the first 10 minutes of paclitaxel administration. There were no IHR-related deaths (Table 3 ).

\section{Risk factors}

ROC curve analysis used to determine cut off values of some variables. The sensitivity and specificity of the following variable cutoffs: age $<54.5$ years, white blood cell count $<7.735 \times 10^{9} / \mathrm{L}$, and absolute eosinophils count $\geq 0.615 \times$ $10 \% / \mathrm{L}$ were $39.2 \%$ and $39.8 \%, 33.8 \%$ and $46.9 \%$, and $84.9 \%$ and $20.2 \%$, respectively. Univariate analysis demonstrated that age $<54.5$ years, stage of cancer $\geq 2$, white blood cell $<$ $7.735 \times 10^{9} / \mathrm{L}$, and postmenopausal status were significant variables correlating with paclitaxel-related IHRs. In multivariate analysis, age $<54.5$ years, stage of cancer $\geq 2$, and white blood cell count $<7.735 \times 10^{9} / \mathrm{L}$ remained significant independent risk factors of IHRs with odds ratios of 2.400 (95\% confidence interval CI: 1.104-5.217, $P=0.027$ ); 2.596 (95\% CI: $1.302-5.177 ; P=0.007$ ), and 2.326 (95\% CI: $1.305-$ 4.145; $P=0.004$ ), respectively (Table 4).

\section{Supportive treatment and management of immediate hyper- sensitivity reactions}

All seventy-four patients who developed IHRs were managed with the immediate termination of paclitaxel infusion and immediately received chlorpheniramine maleate (CPM), CPM plus DEX, or other interventions depending on the severity of reaction. Seventy-two of 74 patients $(97.3 \%)$ recovered from their reaction, they received the remaining volume of paclitaxel with a $50 \%$ reduction of administration rate (Figure 1). Grades of severity, according to NCCN, were

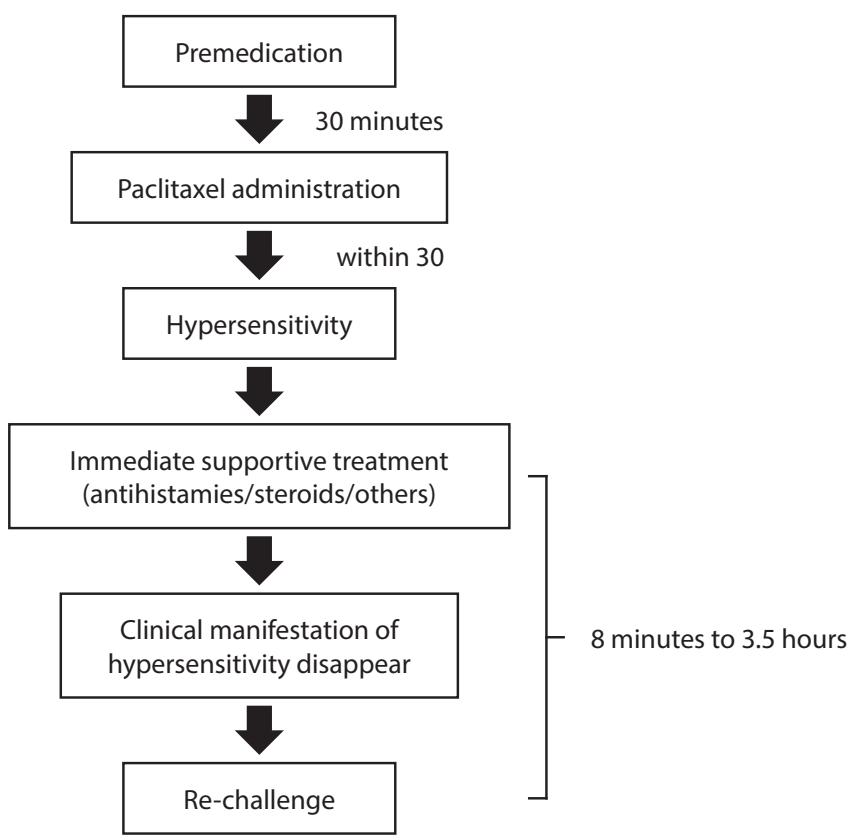

Figure 1. Timeline of the premedication regimen to re-challenge. 
Table 4. Univariate logistic regression analysis and multivariate logistic regression analysis for risk factors of paclitaxel immediate hypersensitivity reactions.

\begin{tabular}{|c|c|c|c|c|c|c|}
\hline \multirow[b]{2}{*}{ Factors } & \multicolumn{3}{|c|}{ Univariate } & \multicolumn{3}{|c|}{ Multivariate } \\
\hline & Odds ratio & $\begin{array}{c}95 \% \\
\text { Confidence } \\
\text { interval }\end{array}$ & $P$ value & Odds ratio & $\begin{array}{c}95 \% \\
\text { Confidence } \\
\text { interval }\end{array}$ & $P$ value \\
\hline Age $<54.5$ years & 2.350 & $1.405-3.932$ & $0.001^{*}$ & 2.400 & $1.104-5.217$ & $0.027^{*}$ \\
\hline Obesity (BMI > 25 kg/m²) & 0.841 & $0.498-1.422$ & 0.519 & - & - & - \\
\hline Ovarian cancer & 0.902 & $0.545-1.493$ & 0.688 & - & - & - \\
\hline Stage of cancer $\geq 2$ & 1.846 & $1.001-3.402$ & $0.049^{\star}$ & 2.596 & $1.302-5.177$ & $0.007^{\star}$ \\
\hline History of drug allergy & 0.953 & $0.511-1.779$ & 0.881 & - & - & - \\
\hline Asthma & 0.507 & $0.063-4.063$ & 0.522 & - & - & - \\
\hline Postmenopausal & 0.481 & $0.273-0.847$ & $0.011^{*}$ & 0.817 & $0.362-1.848$ & 0.628 \\
\hline White blood cell $<7.735 \times 10^{9} / \mathrm{L}$ & 2.22 & $1.311-3.765$ & $0.003^{*}$ & 2.326 & $1.305-4.145$ & $0.004^{*}$ \\
\hline Absolute eosinophils count $\geq 0.615 \times 10^{9} / \mathrm{L}$ & 1.008 & $0.213-4.765$ & 0.992 & - & - & - \\
\hline
\end{tabular}

BMI, body mass index.

mild reactions, severe reactions, and life-threatening reactions, which occurred in 48 patients (64.86\%), 19 patients (25.68\%) and 7 patients $(9.46 \%)$, respectively. Forty-seven $(97.92 \%)$ of 48 patients with mild reactions were successfully re-challenge to paclitaxel after CPM IV or other interventions. Only one patient failed re-challenge after CPM plus DEX. All patients with severe reactions were successfully re-challenged with the remaining paclitaxel after receiving CPM plus DEX or other interventions. The benefits of DEX-containing IHR treatment were analyzed; however, the results did not show a statistically significant difference between DEX-containing regimens and non-DEX-containing regimens. Only one patient was discontinued from paclitaxel and switched to a new regimen without paclitaxel (carboplatin monotherapy) because of a life-threatening reaction (hypotension and wheezing due to bronchospasm). This patient received only carboplatin and

Table 5. Supportive treatment and management of immediate hypersensitivity reactions.

\begin{tabular}{|c|c|c|c|c|c|}
\hline \multirow{2}{*}{$\begin{array}{l}\text { Severity grading by } \\
\text { NCCN }\end{array}$} & \multirow[b]{2}{*}{ Intervention after IHRs } & \multicolumn{2}{|c|}{ Re-challenge } & \multirow[b]{2}{*}{ Discontinuation } & \multirow[b]{2}{*}{ Desensitization } \\
\hline & & $\begin{array}{l}\text { Success } \\
\text { n (\%) }\end{array}$ & $\begin{array}{l}\text { Failure } \\
\text { n }(\%)\end{array}$ & & \\
\hline $\begin{array}{l}\text { Total } \\
\text { (74 patients; } 100 \%)\end{array}$ & Any treatment & $71(95.95)$ & $1(1.35)$ & $1(1.35)$ & $1(1.35)$ \\
\hline \multirow[t]{3}{*}{$\begin{array}{l}\text { Mild } \\
\text { (48 patients; } 64.86 \%)\end{array}$} & Chlorpheniramine maleate $10 \mathrm{mg}$ intravenous & $9(18.75)$ & - & - & - \\
\hline & $\begin{array}{l}\text { Chlorpheniramine maleate } 10 \mathrm{mg} \text { intravenous + } \\
\text { Dexamethasone } 20 \mathrm{mg} \text { intravenous }\end{array}$ & $26(54.16)$ & $1(2.09)$ & - & - \\
\hline & Others & $12(25)$ & - & - & - \\
\hline \multirow[t]{2}{*}{$\begin{array}{l}\text { Severe } \\
\text { (19 patients; } 25.68 \%)\end{array}$} & $\begin{array}{l}\text { Chlorpheniramine maleate } 10 \mathrm{mg} \text { intravenous + } \\
\text { Dexamethasone } 20 \mathrm{mg} \text { intravenous }\end{array}$ & $17(89.50)$ & - & - & - \\
\hline & Others & $2(10.50)$ & - & - & - \\
\hline \multirow[t]{4}{*}{$\begin{array}{l}\text { Life-threatening } \\
\text { (7 patients; } 9.46 \%)\end{array}$} & No & $1(14.30)$ & - & - & - \\
\hline & Chlorpheniramine maleate $10 \mathrm{mg}$ intravenous & $1(14.30)$ & - & - & - \\
\hline & $\begin{array}{l}\text { Chlorpheniramine maleate } 10 \mathrm{mg} \text { intravenous + } \\
\text { Dexamethasone } 20 \mathrm{mg} \text { intravenous }\end{array}$ & $3(42.80)$ & - & $1(14.30)$ & - \\
\hline & $\begin{array}{l}\text { Chlorpheniramine maleate } 10 \mathrm{mg} \text { intravenous + } \\
\text { Ranitidine } 50 \mathrm{mg}+\text { Dexamethasone } 20 \mathrm{mg} \text { intravenous + } \\
\text { Oxygen + NSS + Salbutamol nebulizer + Epinephrine }\end{array}$ & - & - & - & $\begin{array}{l}1(14.30) \\
\text { Fail to desensitize }\end{array}$ \\
\hline
\end{tabular}

IHRs, immediate hypersensitivity reactions; NCCN, national comprehensive cancer network; NSS, $0.9 \%$ sodium chloride. 
achieved to complete remission at the end of carboplatin monotherapy. The remaining patient experienced hypotension and reduction of oxygen saturation. Paclitaxel infusion was also discontinued in this patient, who then underwent desensitization because of the need to use paclitaxel. Desensitization protocol was developed by administering $0.1 \%, 1 \%$, $10 \%$ and $88.9 \%$ of paclitaxel concentration via intravenous infusion for 1 hour, 1 hour, 1 hour and 3 hours, respectively. However, one patient who underwent desensitization failed (Table 5). This patient had IHRs after administration of $0.1 \%$ paclitaxel only 6 minutes. In life-threatening group, Two of 7 patients $(28.6 \%)$ had age $<54.5$ years. Six of 7 patients $(85.7 \%)$ had stage of cancer $\geq 2$. Five of 7 patients $(71.4 \%)$ had white blood cell $<7.735 \times 10^{9} / \mathrm{L}$. One patients who failed desensitization had age $<54.5$ years.

\section{Discussion}

Paclitaxel-based chemotherapy is the mainstay of treatment for gynecologic cancer. In a previous study by Weiss et al., $13.29 \%$ of enrolled patients who did not receive premedication got HSRs, while $8.3 \%$ of patients who received premedication developed HSRs. ${ }^{15}$ Markman et al., Sendo et al., Piovano et al., Ratanajarusiri et al., and Aoyama et al. reported that the incidence of paclitaxel-related HSRs in patient receiving premedication was approximately $10 \%{ }^{7,8,16,17}$ In the present study, $17.79 \%$ of subjects had HSRs, and all subjects received premedication..$^{7-9,16,17}$ This result is higher than that of the previous study. Variation in premedication may have caused this difference considering that our study protocol did not use dexamethasone at 12 hours and 6 hours before paclitaxel administration, unlike that in other studies. ${ }^{6,89}$ All subjects in this present study received premedication 30 minutes before paclitaxel administration (short-regimen), while some studies used DEX $20 \mathrm{mg} 12$ hours or 6 hours infusions before paclitaxel administration (long-regimen), ${ }^{6,89}$ Kwon et al. compared the benefit of short-regimen versus long-regimen premedication. Short-regimen premedication showed a higher rate of HSRs (17.3\%) than long-regimen premedication did (7.5\%). ${ }^{18}$ Kwon's result was comparable to the results of the current study.

In this study, IHRs manifested during the first or second exposure to paclitaxel and always occurred within the first 5 minutes of administration, which is similar to observations of previous studies. ${ }^{8,16}$ No patients died from IHRs. Most enrolled patients experienced IHRs that were mild to severe in concordance with other studies. ${ }^{6,8}$

In the multivariate model, age $<54.5$ years, stage of cancer $\geq 2$, and white blood cell count $<7.735 \times 10^{9} / \mathrm{L}$ exhibited significant correlations with IHRs. In patients aged $<54.5$ years, HSR was increased significantly in concordance with Aoyama et al. ${ }^{9}$ This may be explained by the inverse relationship between younger age and atopic disease as shown in Wolkewitz et al. ${ }^{19}$ Picard et al. showed a direct relationship between atopic disease and risk of paclitaxel-related IHRs. ${ }^{4}$ The relationship between atopic disease and paclitaxel-related IHRs was shown to be caused by reduced lymphocyte production and function in elderly patients. ${ }^{20}$ In this study, cancer stage $\geq 2$ was associated with significantly increased risk of IHRs possibly caused by increased pro-inflammatory cytokines, such as interleukin-2 (IL-2) and tumor necrosis factor. ${ }^{21,22}$ IL-2 was particularly increased in patients with drug allergies. ${ }^{23}$ Here, white blood cell count $<7.735 \times 10^{9} / \mathrm{L}$ was associated with significantly higher risk of IHRs. Surprisingly, to the best of our knowledge, no previous study has reported the relationship between white blood cell count or stage of cancer $\geq 2$ and paclitaxel-related IHRs identified in the present study. Endogenous estrogen levels showed a direct relationship with estrogen receptor on the surface of immunoregulatory cells, which was shown to be important for enhancing antigen-presenting cell function in the development of the allergic reaction. ${ }^{24}$ The present study's findings were in concordance with this concept. Postmenopausal status was a significant protective factor in univariate analysis, but this could not be confirmed in multivariate analysis.

Severity of symptom ranged from mild to life-threatening. These finding were similar to previous studies, except in the reporting of anaphylaxis. ${ }^{6,8,16}$ We found anaphylaxis among patients with IHRs, but the previous studies did not. This may have been due to differences in premedication regimens and rate of paclitaxel administration between these settings. After paclitaxel-receiving patients developed IHRs, infusion of paclitaxel was discontinued and DEX, H1 antihistamine, and $\mathrm{H} 2$ antihistamine were given as supportive treatment according to NCCN Version 2.2018 guidelines. In previous studies, DEX, $\mathrm{H} 1$ antihistamine and $\mathrm{H} 2$ were administered as premedication before the reintroduction of the remaining volume of paclitaxel. However, our practice did not use DEX, $\mathrm{H} 1$ antihistamine, and $\mathrm{H} 2$ before reintroduction of paclitaxel because of the long half-life of the previous supportive medication. Our practice successfully re-challenged $97.91 \%$ and $100 \%$ of patients having initially had mild reactions and severe reactions, respectively.

\section{Conclusion}

In conclusion, the present study found a $17.79 \%$ incidence of paclitaxel-related IHRs, which was higher than in prior studies. ${ }^{7-9,16,17}$ Compare to other studies used similar premedication regimen, the incidence of paclitaxel-related IHRs of our study were higher.7 Symptoms and severity of IHRs were similar to the previous reports. ${ }^{6,8,16}$ This study confirmed that younger age was a risk factor for paclitaxel-related IHRs. Surprisingly, new risk factors were found in this study including stage of cancer $\geq 2$ and white blood cell count $<7.735 \times$ $10^{9} / \mathrm{L}$. Treatment for IHRs in this setting was almost completely successful. These findings inform the careful monitoring of paclitaxel-receiving patient and identify predictive risk factors for IHRs.

\section{Acknowledgments}

The authors declare that there are no conflicts of interest. No sources of funding were used to conduct this study. We gratefully acknowledge the Department of Obstetrics and Gynecology and Department of Pharmacy, Faculty of Medicine Siriraj Hospital, for all information. The authors would like to thank Enago (www.enago.com) for the English language review. 


\section{References}

1. Bitton RJ, Figg WD, Reed E. A preliminary risk-benefit assessment of paclitaxel. Drug Saf. 1995;12(3):196-208.

2. Lee C, Gianos M, Klaustermeyer WB. Diagnosis and management of hypersensitivity reactions related to common cancer chemotherapy agents. Ann Allergy Asthma Immunol. 2009;102(3):179-87.

3. Picard M. Management of Hypersensitivity Reactions to Taxanes. Immunol Allergy Clin North Am. 2017;37(4):679-93.

4. Picard M, Pur L, Caiado J, Giavina-Bianchi P, Galvao VR, Berlin ST, et al. Risk stratification and skin testing to guide re-exposure in taxane-induced hypersensitivity reactions. J Allergy Clin Immunol. 2016;137(4):1154-64 e12.

5. Kadoyama K, Kuwahara A, Yamamori M, Brown JB, Sakaeda T, Okuno Y. Hypersensitivity reactions to anticancer agents: data mining of the public version of the FDA adverse event reporting system, AERS. J Exp Clin Cancer Res. 2011;30:93.

6. Yanaranop M, Chaithongwongwatthana S. Intravenous versus oral dexamethasone for prophylaxis of paclitaxel-associated hypersensitivity reaction in patients with primary ovarian, fallopian tube and peritoneal cancer: A double-blind randomized controlled trial. Asia Pac J Clin Oncol. 2016;12(3):289-99.

7. Ratanajarusiri T, Sriuranpong V, Sitthideatphaiboon P, Poovoravan N, Vinayanuwat C, Parinyanitikul N, et al. A Difference in the Incidences of Hypersensitivity Reactions to Original and Generic Taxanes. Chemotherapy. 2017;62(2):134-9.

8. Sendo T, Sakai N, Itoh Y, Ikesue H, Kobayashi H, Hirakawa T, et al. Incidence and risk factors for paclitaxel hypersensitivity during ovarian cancer chemotherapy. Cancer Chemother Pharmacol. 2005;56(1):91-6.

9. Aoyama T, Takano M, Miyamoto M, Yoshikawa T, Soyama H, Kato K, et al. Is there any predictor for hypersensitivity reactions in gynecologic cancer patients treated with paclitaxel-based therapy? Cancer Chemother Pharmacol. 2017;80(1):65-9.

10. Boulanger J, Boursiquot JN, Cournoyer G, Lemieux J, Masse MS, Almanric K, et al. Management of hypersensitivity to platinum- and taxane-based chemotherapy: cepo review and clinical recommendations. Curr Oncol. 2014;21(4):e630-41.

11. Demoly P, Adkinson NF, Brockow K, Castells M, Chiriac AM, Greenberger PA, et al. International Consensus on drug allergy. Allergy. 2014;69(4): 420-37.
12. Girard M. Conclusiveness of rechallenge in the interpretation of adverse drug reactions. Br J Clin Pharmacol. 1987;23(1):73-9.

13. Simons FE, Ardusso LR, Bilo MB, El-Gamal YM, Ledford DK, Ring J, et al. World allergy organization guidelines for the assessment and management of anaphylaxis. World Allergy Organ J. 2011;4(2):13-37.

14. nccn.org [Internet]. Pennsylvania: National Comprehensive Cancer Network; c2018 [ cited 2018 Mar 15]. Available from: https://www.nccn. org/.

15. Weiss RB, Donehower RC, Wiernik PH, Ohnuma T, Gralla RJ, Trump DL, et al. Hypersensitivity reactions from taxol. J Clin Oncol. 1990;8(7):1263-8.

16. Markman M, Kennedy A, Webster K, Kulp B, Peterson G, Belinson J. Paclitaxel-associated hypersensitivity reactions: experience of the gynecologic oncology program of the Cleveland Clinic Cancer Center. J Clin Oncol. 2000;18(1):102-5.

17. Piovano E, Pivetta E, Modaffari P, Martra F, Baima Poma C, Perotto S, et al. A search for predictive factors for hypersensitivity reactions to paclitaxel and platinum salts in chemotherapy for gynecologic pelvic neoplasms. Gynecol Obstet Invest.2012;74(1):21-7.

18. Kwon JS, Elit L, Finn M, Hirte H, Mazurka J, Moens F, et al. A comparison of two prophylactic regimens for hypersensitivity reactions to paclitaxel. Gynecol Oncol. 2002;84(3):420-5.

19. Wolkewitz M, Rothenbacher D, Low M, Stegmaier C, Ziegler H, Radulescu $\mathrm{M}$, et al. Lifetime prevalence of self-reported atopic diseases in a population-based sample of elderly subjects: results of the ESTHER study. Br J Dermatol. 2007;156(4):693-7.

20. Montecino-Rodriguez E, Berent-Maoz B, Dorshkind K. Causes, consequences, and reversal of immune system aging. J Clin Invest. 2013;123(3):958-65.

21. Illi J, Miaskowski C, Cooper B, Levine JD, Dunn L, West C, et al Association between pro- and anti-inflammatory cytokine genes and a symptom cluster of pain, fatigue, sleep disturbance, and depression. Cytokine. 2012;58(3):437-47.

22. Roxburgh CS, McMillan DC. Cancer and systemic inflammation: treat the tumour and treat the host. Br J Cancer. 2014;110(6):1409-12.

23. Akhmaltdinova LL, Gazalieva MA, Akhmetova SB. Levels of cytokines in drug hypersensitivity. Cent Eur J Immunol. 2017;42(4):354-7.

24. Bonds RS, Midoro-Horiuti T. Estrogen effects in allergy and asthma. Curr Opin Allergy Clin Immunol. 2013;13(1):92-9. 